\title{
Effects of solid-liquid separation and storage on monensin attenuation in dairy waste management systems
}

Sarah C. Hafner ${ }^{\mathrm{a}}$, Naoko Watanabe ${ }^{\mathrm{a} 1}$, Thomas Harter ${ }^{\mathrm{a}}$, Brian A. Bergamaschi ${ }^{\mathrm{b}}$, Sanjai J. Parikh ${ }^{\mathrm{a}^{*}}$

a Department of Land, Air, and Water Resources, University of California, One Shields Avenue, Davis, CA 95616

${ }^{\mathrm{b}}$ U.S. Geological Survey, Placer Hall 6000 J Street, Sacramento, CA 95819

*Corresponding author: sjparikh@ucdavis.edu

\section{Abstract}

Environmental release of veterinary pharmaceuticals has been of regulatory concern for more than a decade. Monensin is a feed additive antibiotic that is prevalent throughout the dairy

14 industry and is excreted in dairy waste. This study investigates the potential of dairy waste 15 management practices to alter the amount of monensin available for release into the

16 environment. Analysis of wastewater and groundwater from two dairy farms in California

17 consistently concluded that monensin is most present in lagoon water and groundwater

18 downgradient of lagoons. Since the lagoons represent a direct source of monensin to

19 groundwater, the effect of waste management, by mechanical screen separation and lagoon

20 aeration, on aqueous monensin concentration was investigated through construction of lagoon

21 microcosms. The results indicate that monensin attenuation is not improved by increased solid-

22 liquid separation prior to storage in lagoons, as monensin is rapidly desorbed after dilution with

23 water. Monensin is also shown to be easily degraded in lagoon microcosms receiving aeration,

24 but is relatively stable and available for leaching under typical anaerobic lagoon conditions.

\footnotetext{
${ }^{1}$ Present Address: Faculty of Engineering, Hokkaido University, Kita 13 Nishi 8, Kita-ku, Sapporo, Hokkaido, Japan 060-8628 
Keywords

27 antibiotics, groundwater, manure management, monensin

Introduction

Monensin is a polyether ionophore antibiotic used exclusively for veterinary applications,

31 specifically in poultry and cattle to treat coccidiosis and enhance growth (Fig. 1) (Russell and

32 Houlihan, 2003). Monensin is also used in lactating dairy cattle to increase milk productivity,

33 making monensin one of the few feed additives approved for lactating cattle in the United States

34 (US FDA, 2004; NMFP, 2015). While standards on antimicrobial use have typically been more

35 stringent in other countries than the US, monensin continues to be used as a growth promoting

36 feed additive worldwide (Maron et al., 2013). Due to its high toxicity profile and the largely

37 unknown fate in the environment relative to other antimicrobials, monensin is 1 of 13 veterinary

38 active ingredients listed as high priority for detailed risk assessment out of 83 investigated

39 (Capleton et al., 2006).

The potential for high monensin use in dairies raises concerns of significant monensin

41 loading into the environment through manure management. Dairy manure, which contains

42 excreted antibiotics and metabolites, is often collected by flushing freestalls. Solids are then

43 separated from diluted manure through a variety of techniques. Solids are commonly separated

44 by settling basin sedimentation, which uses gravity to remove the solids. Mechanical screening

45 of manure is another common technique, often followed by further separation by settling. After

46 solid-liquid separation, the liquid fraction is stored in a lagoon and often applied to forage crop

47 fields as a soil amendment. This practice is concerning in California, where dairies are one of the

48 state's most prevalent concentrated animal feeding operation (CAFO) industries (NASS, 2014). 
49 Further, most of California's dairies are located in the San Joaquin Valley (CDFA, 2009), a

50 topographically flat region of predominantly alluvial and fluvial unconsolidated aquifers with

51 some areas of shallow water tables, making them particularly vulnerable to contamination.

52 There are two potential pathways for monensin to reach groundwater: by direct leaching

53 from the production area and through the waste management system, such as lagoon storage and

54 manure application to fields. Previous research in a California dairy system has shown that

55 contamination of groundwater via waste storage is considerable, while liquid manure application

56 to irrigated crops is not a significant source of monensin to groundwater (Watanabe et al., 2008;

57 Hafner et al., 2016). Once released into the soil, processes for reduction of available monensin

58 appear to be rapid and include degradation and sorption to soil (Carlson and Mabury, 2006;

59 Davis et al., 2006; Sassman and Lee, 2007; Song et al., 2010).

Reducing monensin concentrations in the lagoon will reduce a major groundwater

61 contamination pathway. The primary goal of this study is to investigate the effects that waste

62 management practices have on final aqueous monensin concentrations in manure slurries. In

63 order to fully assess monensin distribution in groundwater beneath dairies, additional samples

64 were collected from the two dairy systems monitored in Watanabe et al. (2008). Groundwater,

65 flush lane, and lagoon water samples were collected during four sampling events over two years.

66 Laboratory manure microcosms were then constructed to determine the potential effect of waste

67 management practices on monensin attenuation. Given that monensin is nearly exclusively

68 excreted in the feces (Donoho et al., 1978), the effect of solid-liquid separation by screening (2

$69 \mathrm{~mm})$ on final lagoon monensin concentrations is investigated. Short-term microcosms $(<48 \mathrm{~h})$

70 were constructed to evaluate the effect that settling basin detention time has on final monensin

71 concentration. Long-term microcosms were used to determine these same effects on a time scale 
72 more relevant to lagoon storage (weeks), and included a treatment for the effects of aeration on

73 monensin transformation.

75 Materials and Methods

$76 \quad 2.1$ Dairy Study Sites

77 Two dairy farms in the San Joaquin Valley of California were studied. Detailed 78 descriptions of the site hydrogeology are given in Harter et al. (2002). Groundwater levels in the 79 study area range from 2 to $5 \mathrm{~m}$, with a well-drained sandy loam as the dominant surface soil 80 texture. Monitoring wells (MWs) are $5 \mathrm{~cm}$ in diameter and 7 to $10 \mathrm{~m}$ in depth, with screening

81 below 2 or $3 \mathrm{~m}$. Wells capture recent recharge from irrigated fields, lagoon leachate, or corral 82 recharge. Dairy maps and monitoring well locations are provided in Supporting Figure S1.

83 On both dairies, concrete-lined freestalls are flushed with lagoon water three to four times

84 per day to collect waste. Flushed manure then undergoes solid-liquid separation before collection

85 of the liquid fraction into a lagoon. Dairy I separates solids by mechanical screen and settling 86 basins, while Dairy II utilizes only settling basins.

87 Groundwater, flush lane, and lagoon water samples were collected during four sampling 88 campaigns in the fall (Oct. 17-18, 2006), spring (April 26 and May 22, 2007), summer (Sept.489 5, 2007) and winter (Jan. 2-3, 2008) from Dairy I and Dairy II. Due to restricted accessibility, 90 not all wells were sampled at each sampling date. Methods of groundwater, flush lane, and 91 lagoon water sampling are detailed in Watanabe et al. (2008).

92

$93 \quad 2.2$ Manure Collection 
95 Teaching and Research Facility in Davis, CA. Treatment samples were obtained from milking

96 cows consuming monensin at a dose of $6 \mathrm{mg} \mathrm{lb}^{-1}$ dry matter. Manure without monensin was also

97 collected from an organic dairy farm in Orland, CA, for use as a negative control. The feed

98 rations for both dairies are described in the Supporting Material. Fresh manure was shoveled into

99 buckets lined with plastic bags and stored at $4{ }^{\circ} \mathrm{C}$. Treatment dairy manure was collected directly

100 from the bedding while the organic control manure was collected at the end of the flush lane.

101 Total solids (TS) was determined by taking three representative samples ( 25 g) from both the

102 treatment and control manure and oven drying at $105^{\circ} \mathrm{C}$, cooling in a desiccator, and weighing

103 remaining solids. The process was repeated until samples differed by $<50 \mathrm{mg}$ over one hour of

104 drying (Eaton et al., 1995). The bedding material in the treatment manure (sand) was removed

105 from final samples prior to determining TS. Fecal samples were then diluted with $18.2 \mathrm{M} \Omega \cdot \mathrm{cm}$

106 water to reach an initial TS of 3\% for use in all experiments. Diluted manure for screened

107 treatments was passed through a $2 \mathrm{~mm}$ sieve with gentle stirring and light pressing of solids, and

108 TS was determined for the final screened suspension. Due to the volume of diluted manure

109 required for long-term lagoon microcosms with and without aeration, two separate dilutions were

110 made and distributed throughout the time points.

111

$112 \quad 2.3$ Chemical Analysis

113 Chemical preparation for dairy site samples is described in Watanabe et al. (2008). The 114 analysis of monensin and nigericin by liquid-chromatography mass-spectrometry for the 115 microcosm study is detailed in the Supplemental Material. 
Quality control for dairy site sample analysis is described in Watanabe et al. (2008).

117 Quality control for microcosm experiments was evaluated by performing spike-recovery

118 experiments on manure extracts. Diluted manure was screened to $<2 \mathrm{~mm}$ (2.3\% TS organic

119 control, 1.2\% TS treatment), centrifuged in $40 \mathrm{~mL}$ fluorinated ethylene propylene (FEP) Nalgene

120 Oak Ridge tubes (20 min at $20,500 \times g$ ), and filtered to $0.3 \mu \mathrm{m}$ using stacked glass fiber filters

$121(1.3 \mu \mathrm{m}, 0.7 \mu \mathrm{m}, 0.3 \mu \mathrm{m})$ on glass frit filtration assemblies. Extracts $(25 \mathrm{~mL})$ were fortified to

$1226.6 \mu \mathrm{g} \mathrm{L}^{-1}$ with monensin and $6.4 \mu \mathrm{g} \mathrm{L}{ }^{-1}$ with nigericin. Nigericin is an ionophore not used by

123 the dairy industry, and was therefore appropriate to use as a surrogate to evaluate analyte loss.

124 Samples were mixed for $15 \mathrm{~min}$ at $130 \mathrm{rpm}$ on a platform shaker (New Brunswick Scientific,

125 Edison, NJ) before solid-phase extraction (SPE) with Waters Oasis hydrophilic-lipophilic

126 balance (HLB) cartridges (3 mL, $60 \mathrm{mg}$ ). Cartridges were conditioned with $3 \mathrm{~mL}$ methanol and

127 equilibrated with $6 \mathrm{~mL}$ water before sample addition. Cartridges were then washed with $6 \mathrm{~mL}$

128 water before drying and eluting with $2 \mathrm{~mL}$ methanol. Recovery samples for each treatment were

129 prepared in triplicate, with triplicate unfortified samples. Monensin recovery from filtered

130 organic manure was $87.6 \%(4.3 \% \mathrm{CV})$, and recovery from filtered treatment manure was $87.1 \%$

131 (9.3\% CV). Nigericin recovery from filtered treatment manure averaged $82.2 \%(4.5 \% \mathrm{CV})$.

132

$133 \quad 2.4$ Extractable Monensin from Manure

134 The effect of the manure quantity on monensin concentration for both screened and 135 unscreened manure was evaluated by three manure dilutions. Wet manure (90, 110, or 130 g) 136 was weighed into a beaker and diluted to $500 \mathrm{~mL}$ with water, for final amounts of 18 , 22, and 137 26\% manure (wet weight). Each manure dilution was performed three times. As each solution 138 was stirred, aliquots were removed for measuring TS (triplicate) and monensin. The remaining 
139 manure slurry was then screened with a $2 \mathrm{~mm}$ sieve, and the filtrate analyzed as before.

140 Monensin samples were centrifuged, filtered, and extracted by SPE as previously described,

141 without the addition of nigericin. Total solids were determined as previously described, but on $142<10$ g of wet sample.

143 Extractable monensin from wet manure was evaluated by multiple extractions of manure

144 with either water or methanol. Water-extractable monensin was determined by combining about $14510 \mathrm{~g}$ of wet manure with $30 \mathrm{~mL}$ water, briefly vortexing, and rotating end-over-end for $1.5 \mathrm{~h}$.

146 Samples were centrifuged for $20 \mathrm{~min}$ at $20,500 \times \mathrm{g}$, and the supernatant removed and extracted 147 by SPE as previous water samples. Water was added to tubes and the process repeated for a total 148 of three water extractions. Similar protocol was followed for three methanol extractions, with the 149 exception that the second and third extractions were centrifuged for 10 min at $14,200 \times g$ and $1509,100 \times g$, respectively. Samples $(10 \mathrm{~g})$ were extracted with methanol $(30 \mathrm{~mL})$ in a sonicating 151 bath for 10 min per extraction. After centrifugation, supernatant was decanted and $30 \mathrm{~mL}$ fresh 152 methanol added to tubes. Samples were vortexed (30 s) and shaken to resuspend the solids, in 153 addition to 5 min of sonication since the organic manure (negative control) was difficult to 154 resuspend. This process was repeated for a total of three extractions.

$156 \quad 2.5$ Microcosms

157 Amber bottles (1-L) were filled with diluted manure for each treatment (unscreened, 158 screened, organic screened control) for the short-term settling basin representation. Samples for 159 each time point and treatment were prepared in triplicate for destructive sampling. At the stated 160 time points, the sample bottles were shaken and aliquots were removed for centrifugation for 20 $161 \mathrm{~min}$ at $20,500 \times g$ and filtered to $0.3 \mu \mathrm{m}$. Electrical conductivity (EC) and $\mathrm{pH}$ were measured on 
162 the remaining manure in bottles on a stir plate. Filtered samples were then subsampled for SPE

163 analysis $(25 \mathrm{~mL})$ with nigericin $(1 \mu \mathrm{g})$ added to samples just before extraction, and the remainder

164 of filtrate was stored at $-20^{\circ} \mathrm{C}$ until analysis for dissolved organic carbon (DOC), nitrate, and

165 ammonium. Dissolved organic carbon and $\mathrm{N}$ analyses are detailed in the Supporting Materials.

166 Long-term microcosms were prepared similarly to short-term microcosms. Samples not

167 receiving aeration were capped and stored at ambient temperature next to aerated samples.

168 Aeration was achieved by bubbling compressed ambient air through $6 \mathrm{~mm}$ diameter glass

169 pipettes at an approximate rate of $5 \pm 1 \mathrm{~cm}^{3} \mathrm{~s}^{-1}$ into uncapped samples. Samples were checked

170 periodically to adjust air input to each sample for consistency. Samples were analyzed similar to

171 settling basin samples.

172

173 2.6 Statistics: Lagoon Microcosms

174 R software was used to determine statistical significance of values within treatments. The 175 data was first evaluated with the Shapiro-Wilk test, Levene's test, then significance determined 176 by Tukey’s honest significant difference test $(\alpha=0.05)$.

\section{Results and Discussion}

$179 \quad 3.1$ Monensin on Dairies

180 Monensin was consistently detected in all of the lagoon water samples at Dairy I and

181 Dairy II (Table 1). The average concentrations in the lagoons are $5.6 \pm 9.2 \mu \mathrm{g} \mathrm{L}{ }^{-1}$ at Dairy I and $1824.1 \pm 2.3 \mu \mathrm{g} \mathrm{L}{ }^{-1}$ at Dairy II over all four sampling campaigns. The discrepancy in monensin 183 measurements between sampling dates can be explained by both spatial variability within the 184 lagoon and temporal variability. Lagoon water was collected from 12 different locations around 
185 the lagoon and composited to reduce the spatial variability of the surface water, but water was

186 not able to be collected from either the central or deeper parts of the lagoon. Temporal variability

187 is less likely compared to antibiotics that are administered on sick animals, since monensin is

188 administered daily as a feed additive. However, the observed seasonal variation of monensin in

189 the lagoon can be attributed to rainfall dilution (October to April), summer evaporation, and

190 irrigation needs (primarily summer). Though there is variability, monensin is consistently

191 detected in lagoons on all sampling dates, representing a constant source of monensin available

192 for leaching to groundwater.

193 Monensin was detected once in MW 7 near the lagoon and irrigated forage field at Dairy

194 I, and sporadically in MW 1, 2, and 10 at Dairy II. At Dairy II, MW 1 is near freestalls, the feed 195 storage area, and the lagoon, while MW 2 is close to freestalls and dry cow housing area. The 196 range of concentrations of monensin in these wells was often lower than the lagoon wells on 197 each dairy (MW 3), where monensin was most frequently detected. These findings emphasize 198 that monensin contamination of groundwater on a dairy is most likely to result from waste 199 management practices, particularly the lagoons. The lagoons on these dairies were constructed 200 several decades ago, and the clay liners are known to be leaking. These lagoons continuously 201 supply monensin-containing water to groundwater, while the production area receives only 202 intermittent and spatially heterogeneous loading. Additionally, the production area and corrals 203 have very low infiltration rates relative to lagoon, since the lagoon supplies a much larger 204 pressure head to soil.

205

2063.3 Extractable Monensin from Manure 
208 methanol-extractable monensin, more representative of total monensin, and water-extractable

209 monensin, relevant to the dairy system. The total monensin recovered by three subsequent

210 methanol extractions is $1351 \mu \mathrm{g} \mathrm{kg}{ }^{-1}$ (dry weight), while water extractions recovered only 429

$211 \mu \mathrm{gg}^{-1}$ (Fig. 2). The third extract of the methanol extraction contained only 3.6\% of the total

212 monensin removed from that method, suggesting that three extractions are nearly exhaustive for

213 removal of methanol-extractable monensin by sonication. Water extraction only recovered

$21431.8 \%$ of the total methanol-extractable monensin after three washes. There was also a linear

215 decrease in the amount of monensin removed with each methanol extraction $(61.7 \%, 34.7 \%$,

216 3.6\%), while the first water extraction removed the most water-extractable monensin (70.2\%)

217 followed by two extractions of similar concentrations (17.1\%, 12.7\%). This suggests that most

218 water-extractable monensin is removed into the liquid phase during the initial manure dilution on

219 a dairy, while the methanol extraction demonstrates that there is much more monensin available

220 for desorption during manure mineralization in a lagoon or possible transport on colloids.

\section{3.4 Solid-Liquid Separation}

223 Short-term $(<36 \mathrm{~h})$ microcosms were constructed to be representative of the chemical

224 changes that happen in diluted manure immediately after flushing and in settling basins. Results

225 indicate that the initial and final monensin concentration does not change significantly over a $22636 \mathrm{~h}$ period, though concentrations increase slightly from 0 to $20 \mathrm{~h}$ (unscreened manure) and 0 to

$22725.6 \mathrm{~h}$ (screened manure) (Fig. 3). While statistically significant, this difference in concentration 228 of $\sim 2 \mu \mathrm{g} \mathrm{L}^{-1}$ is not realistically important in a dairy setting. Most desorption of monensin from 
manure occurs rapidly after dilution (Fig. 3), and settling basin detention time does not

230 substantially affect the concentration of monensin entering the lagoons.

232 aqueous monensin concentration during lagoon storage. Samples without aeration demonstrate

233 the stability of monensin in these anaerobic lagoons, particularly when viewed in the context of

234 samples which received aeration (Fig. 4). However, the effect of manure screening on aqueous

235 monensin concentrations is not consistent between short-term and long-term microcosm

236 experiments. This inconsistency may be attributable to differences in the TS measured between

237 the screened manure in each experiment. The average TS remained similar for unscreened

238 samples between experiments (3.1-3.2\%), and materials contributing to TS variability are less

239 likely to affect monensin concentrations in these samples (e.g., undigested hay). The TS of

240 screened samples instead consists of fine manure particles which may sorb more monensin, and

241 increases up to $29.5 \%$ from the short-term to long-term experiments (from 1.2\% to 1.3-1.5\% TS)

242 (Fig. 5). This increase in TS between the experiments could account for the reversal in effect of

243 screening on aqueous monensin concentrations.

244 The role of TS percentage and screening was explored through comparing aqueous

245 monensin concentrations from different manure dilutions (18, 22, and 26\% manure, wet weight).

246 The results clearly demonstrate that aqueous monensin is increasing as the initial manure (or

247 final TS) increases, and that the concentration of monensin is not affected by screening of

248 manure (Fig. 6). This is consistent with findings from the short-term microcosms, which

249 establish that monensin is desorbed from manure rapidly following dilution. Therefore, the

250 practice of screening diluted manure does not result in a decrease in the final aqueous monensin

251 concentration in the liquid fraction. Similar results have been demonstrated for two classes of 
252 steroid hormones (estrogens, androgens) in mechanically separated swine waste, which show no

253 significant difference ( $>0.01$ ) in steroid concentration relative to total solids between raw and

254 liquid manure after various separation methods (Hansen et al., 2015). Collectively, these results

255 suggest that solids separation may not be sufficient for reducing environmental loading with

256 agrochemicals, even those which would be expected to primarily associate with the solid 257 fraction.

258 Methanol extractions of the dairy manure also reveal that a considerable amount of 259 monensin remains in the solid portion relative to the amount desorbed. However, solid manure 260 products are often composted before reuse as bedding material on dairies, a practice which has 261 been demonstrated to reduce monensin concentrations in animal manure (Dolliver et al., 2008;

262 Kang et al., 2013). This reinforces the postulation that management of liquid waste is most 263 critical when assessing monensin fate on dairies.

\subsection{Aeration on Monensin Dissipation}

Monensin concentrations in aerated samples are corrected for evaporation of water over

267 the time period, though final monensin concentration was greatly reduced in all aerated samples

268 regardless of correction. The reduction of monensin in aerated samples is likely due to

269 transformation, by either indirect oxidation or microbial transformations, as monensin has a very

270 low Henry's constant (low volatility) and is known to undergo biotransformation (Thiele-Bruhn,

271 2003; Sun et al., 2014). Monensin is also known to undergo hydrolysis in acidic conditions;

272 however, the $\mathrm{pH}$ in aerated samples increased to 7.5 and 8.3 (unscreened, screened) while non-

273 aerated samples decreased to 6.4 and 6.5 after 5 wk (Fig. S2). The high $\mathrm{pH}$ of the aerated

274 samples indicates that hydrolysis is not a transformation pathway (Sun et al., 2014). The 
275 decrease in DOC (Fig. S3) and ammonium (Fig. S4) in aerated samples relative to capped 276 samples also supports transformation by microbial activity. Dissolved organic carbon represents 277 a readily available $\mathrm{C}$ source for microbes, released as $\mathrm{CO}_{2}$ after respiration. Ammonium loss is 278 presumed to be through rapid denitrification and gas loss, as nitrate detection was low when 279 present at all.

280 The rate of average monensin transformation was determined for both aerated and non281 aerated long-term microcosms. Monensin reduction in aerated samples was determined to be 282 first-order, and the resultant reaction rate coefficients $(\mathrm{k})$ for monensin in screened and 283 unscreened samples are nearly identical ( 0.051 and $0.049 \mathrm{~d}^{-1}$ ), leading to similar half-lives of 28413.7 and $14.1 \mathrm{~d}$, respectively. These half-lives can be verified in the data through two half-lives 285 by calculating the amount of monensin expected at 14 and 28 days (Fig. 3). Samples without 286 aeration do not exhibit the same reduction in monensin. However, for a crude comparison, 287 analysis of screened and unscreened samples following first-order dissipation (screened $r^{2}=0.79$, 288 unscreened $\left.r^{2}=0.85\right)$ again have similar rate coefficients $\left(\mathrm{k}=0.004\right.$ and $\left.0.005 \mathrm{~d}^{-1}\right)$, resulting in 289 half-lives of 161 and 133 d, respectively. If analyzed by zero-order kinetics (screened $r^{2}=0.78$, 290 unscreened $r^{2}=0.85$ ), half-lives are 122 and $103 \mathrm{~d}$, respectively. While these results cannot be 291 verified from the data, they again demonstrate that screened and unscreened samples behave 292 similarly, and clearly show that aerated samples benefit from much faster monensin degradation. 293 This is similar to observations of monensin biotransformation in mixed cultures derived from 294 poultry litter and litter-amended soil, which demonstrated much faster transformation under 295 aerobic versus anoxic conditions (Sun et al., 2014). In addition to aeration resulting in shorter 296 half-lives, the potential for difference in reaction order (zero- versus first-order) will affect how 297 monensin degrades in each system. The half-lives of first order reactions (i.e., aerated samples) 
298 are independent of concentration, while zero-order half-lives increase as the initial concentration

299 increases (Whitten et al., 2004). This means that degradation would slow with increased

300 monensin inputs, though the reaction order of non-aerated samples cannot be ascertained from

301 the existing data.

302 While aeration in the microcosms greatly reduces monensin, there are important 303 considerations when applying microcosm data to the farm-scale. The first is aeration efficiency, 304 as the ratio of bubble volume to slurry is much higher in microcosms than would be expected on 305 a farm scale, accelerating aeration and the degradation of monensin in microcosms. Another 306 consideration is water evaporation, which results in a more concentrated manure slurry with 307 respect to leachable ions. However, the benefits of aeration for managing odors, nitrogen, and 308 pathogens in the final manure slurry may outweigh the cost of a more concentrated slurry 309 (Westerman and Zhang, 1997).

310 There are multiple methods of aerating manure slurries, including compressed air (as 311 replicated here), mechanical mixing (surface and subsurface), pumped liquid, or a combination 312 of compressed air and mechanical mixing (Cumby, 1987). The use of compressed air benefits 313 from having a simple, low cost design and the ability to add to existing lagoons. However, 314 aeration efficiency is hindered in large, shallow ponds due to low contact time of bubbles with 315 the manure slurry as they rise. While smaller bubbles (ideally $<5 \mathrm{~mm}$ ) will rise more slowly with 316 a higher gas-transfer surface area help overcome this issue, manure slurries also tend to clog 317 small bubble diffusers, limiting their effectiveness (Cumby, 1987; Singleton and Little, 2006). 318 Operating costs are also a limiting factor when considering the use of aeration on a farm scale 319 (Westerman and Zhang, 1997). These limitations are significant and often preclude the 320 widespread use of lagoon aeration. Similar aeration systems are commonly employed in lakes, 
321 reservoirs, and ponds to manage anoxic conditions, often facing comparable issues of cost and

322 fouling. Additional research into practical designs for aeration of dairy lagoons would be 323 valuable.

324

Environmental Impact

$326 \quad$ Groundwater analyses from monitoring wells distributed around two California dairies 327 identify lagoon leakage as the most likely source of groundwater contamination with monensin. 328 However, investigation into manure solid-liquid separation techniques commonly used on 329 dairies, such as manure screening and settling basins, reveals that monensin is not attenuating 330 during waste separation processes. In fact, monensin is desorbed from manure almost 331 immediately after dilution. The implications of this research on groundwater contamination 332 extend to other abundant veterinary pharmaceuticals found in lagoon-stored manure on CAFOs 333 (e.g., dairy and swine). Monensin is primarily excreted in feces and is relatively hydrophobic $334\left(\log \mathrm{K}_{\mathrm{ow}}=2.75\right)$ compared to many other agrochemicals (Thiele-Bruhn, 2003; Elanco Products 335 Company, 1989) suggesting that the current waste management system is also likely inadequate 336 for processing chemicals which are more water-soluble and/or excreted in urine. While there are 337 drawbacks to all waste management practices, the elimination of waste storage lagoons or further 338 treatment of lagoon water could remove a primary and direct source of many contaminants to 339 groundwater. Composting of the whole manure or aeration of lagoons would increase biological 340 activity and degradation of agrochemicals, such as monensin. Since common dairy waste 341 management techniques are not effective for removing agrochemicals from manure, further 342 research into lagoon treatments is needed for reducing contaminant concentrations in dairy 343 lagoons and the underlying groundwater. 


\section{Acknowledgments}

346 The authors are grateful to Dana Erickson for initiating the proposal and Jeff Palsgaard at

347 MCDEH for his assistance. Funding for this research was provided by CALFED Bay-Delta

348 Authority Drinking Water Program in a grant to the Merced County Department of

349 Environmental Health and administered by the California State Water Resources Control Board

350 (03-244-555-01), the USGS Cooperative Water Program, and the California Department of Food

351 and Agriculture (07-0893). Additional funding was provided by the United States Department of

352 Agriculture (USDA) National Institute of Food and Agriculture (NIFA) through Hatch Formula

353 Funding and multistate regional projects W-3045. 


\section{References}

California Department of Food and Agriculture (CDFA). California Agricultural Directory 2008-2009. 2009 Available at https://www.cdfa.ca.gov/statistics/PDFs/ResourceDirectory_2008-2009.pdf (verified 6 May 2016).

Capleton, A.C.; Courage, C.; Rumsby, P.; Holmes, P.; Stutt, E.; Boxall, A.B.; Levy, L.S. Prioritising veterinary medicines according to their potential indirect human exposure and toxicity profile. Toxicol. Lett. 2006 163:213-223. DOI:10.1016/j.toxlet.2005.10.023

Carlson, J. C.; Mabury, S.A. Dissipation kinetics and mobility of chlortetracycline, tylosin, and monensin in an agricultural soil in Northumberland County, Ontario, Canada. Environmental Toxicology and Chemistry 200625 (1): 1-10. DOI: 10.1897/04-657R.1

Cumby, T.R. A review of slurry aeration: Performance of Aerators. J. Agric. Eng. Res. 1987 36: 175-206. DOI:10.1016/0021-8634(87)90073-4

Davis, J. G.; Truman, C.C.; Kim, S.C.; Ascough, J.C.; Carlson K. Antibiotic Transport via Runoff and Soil Loss. Journal of Environmental Quality 2006 35: 2250-2260. DOI:10.2134/jeq2005.0348

Dolliver, H.; Gupta, S.; Noll, S. Antibiotic degradation during manure composting. Journal of Environmental Quality 2008 37: 1245-1253. DOI:10.2134/jeq2007.0399

Donoho, A.; Manthey; J.; Occolowitz; J.; Zornes, L. Metabolism of monensin in the steer and rat. Journal of Agricultural and Food Chemistry 1978 26: 1090-1095. DOI: 10.1021/jf60219a005

Eaton, A.D.; Clesceri, L.S.; Greenberg, A.E.; Franson, M.A.H. Standard methods for the examination of water and wastewater. Washington, DC 1995: American Public Health Association.

Elanco Products Company. Environmental assessment for the use of Rumensin premixes in the feed of beef cattle for the prevention and control of coccidiosis. 1989 Elanco Products Company, Indianapolis, IN.

Hafner, S.C.; Harter, T.; Parikh, S.J. Evaluation of monensin transport to shallow groundwater after irrigation with dairy lagoon water. Journal of Environmental Quality 201645 (2): 480-487. DOI:10.2134/jeq2015.05.0251

Hansen, M.; Björklund, E.; Popovic, O.; Jensen, L.S.; Jacobsen, C.S.; Sedlak, D.L.; HallingSørensen, B. Animal manure separation technologies diminish the environmental burden of steroid hormones. Environmental Science \& Technology Letters 2015 2:133-137. DOI: 10.1021/acs.estlett.5b00059

Harter, T.; Davis, H.; Mathews, M.C.; Meyer, R.D. Shallow groundwater quality on dairy farms with irrigated forage crops. Journal of Contaminant Hydrology 2002 55: 287-315. DOI:10.1016/S0169-7722(01)00189-9

Kang, D.H.; Gupta, S.; Rosen, C.; Fritz, V.; Singh, A.; Chander, Y.; Murray, H.; Rohwer, C. Antibiotic uptake by vegetable crops from manure-applied soils. Journal of Agricultural and Food Chemistry 2013 61: 9992-10001. DOI: 10.1021/jf404045m

Maron, D.F.; Smith, T.J.S.; and Nachman, K.E. Restrictions on antimicrobial use in food animal production: an international regulatory and economic survey. Globalization and Health; 2013 9:48. DOI: 10.1186/1744-8603-9-48 
McNab, W.W.; Singleton, M.J.; Moran, J.E.; Esser, B.K. Assessing the Impact of Animal Waste Lagoon Seepage on the Geochemistry of an Underlying Shallow Aquifer. Environmental Science \& Technology 2007 41: 753-758. DOI: 10.1021/es061490j

National Agricultural Statistics Service (NASS). 2012 Census of Agriculture, United States Summary and State Data, Volume 1, Geographic Area Series, Part 51. (AC-12-A-51). Washington, DC, 2014: U.S. Department of Agriculture.

National Milk Producers Federation (NMFP). National Dairy FARM Program: Farmers Assuring Responsible Management ${ }^{\mathrm{TM}}$ Milk and Dairy Beef Drug Residue Prevention Manual. 2015 Available at http://www.nationaldairyfarm.com/sites/default/files/2016-ResidueManual.pdf (verified 6 May 2016).

Russell, J. B.; Houlihan, A.J. Ionophore resistance of ruminal bacteria and its potential impact on human health. FEMS Microbiology Reviews; 2003 27: 65-74. DOI: 10.1016/S01686445(03)00019-6

Sassman, S. A.; Lee, L.S. Sorption and degradation in soils of veterinary ionophore antibiotics: Monensin and lasalocid. Environmental Toxicology and Chemistry 2007 26: 1614-1621. DOI: 10.1897/07-073R.1

Singleton, V.L; Little, J.C. Designing Hypolimnetic Aeration and Oxygenation Systems - A Review. Environ. Sci. Technol. 200640 (24), 7512-7520; DOI: 10.1021/es060069s.

Song, W.; Ding, Y.; Chiou, C.T.; Li, H. Selected Veterinary Pharmaceuticals in Agricultural Water and Soil from Land Application of Animal Manure. Journal of Environmental Quality 2010 39: 1211-1217. DOI:10.2134/jeq2009.0090

Sun, P.; Huang, C.; Pavlostathis, S.G. Inhibition and biotransformation potential of veterinary ionophore antibiotics under different redox conditions. Environmental Science and Technology 2014 48: 13146-13154. DOI: 10.1021/es503005m

Thiele-Bruhn, S. Pharmaceutical antibiotic compounds in soils - a review. J. of Plant Nutr. Soil Sci. 2003166 (2): 145-167. DOI: 10.1002/jpln.200390023

US Food and Drug Administration. New Animal Drugs; Monensin. Federal Register 692004 (227): 68783-68784. http://www.fda.gov/ohrms/dockets/98fr/04-26091.pdf (accessed 6 May 2016).

Watanabe, N.; Harter, T. H.; Bergamaschi, B.A. Environmental occurrence and shallow ground water detection of the antibiotic monensin from dairy farms. Journal of Environmental Quality 2008 37: S78-S85 DOI:10.2134/jeq2007.0371

Westerman, P.W.; Zhang, R.H. Aeration of livestock manure slurry and lagoon liquid for odor control: A review. Applied Engineering in Agriculture 199713 (2): 245-249. DOI: 10.13031/2013.21596

Whitten, K.W.; Davis, R.E.; Peck, M.L.; Stanley, G.G. General Chemistry, Seventh ed.; Belmont, CA: Brooks/Cole - Thomson Learning, 2004. 
Table 1. Monensin concentrations found in dairy lagoon, flush lane, and groundwater samples. Monitoring wells not shown were either not measured or had below detection levels of monensin for all sampling dates. All samples are analyzed in triplicate. Numbers in parentheses represent standard deviations. $\mathrm{BD}=$ below detection, $\mathrm{NC}=$ not collected.

\begin{tabular}{lccccc}
\hline Location & Well ID & Oct 2006 $^{\dagger}$ & Apr/May 2007 & Aug/Sept 2007 & Jan 2008 \\
\hline Dairy I & & & & & \\
Lagoon & & NC & $16.24(1.26)$ & $0.41(0.03)$ & $0.14(0.001)$ \\
Flush lane & & $1.89(0.66)$ & $3.58(0.16)$ & $0.54(0.04)$ & $0.17(0.003)$ \\
Calf hutch flush & & $0.64(0.17)$ & $0.42(0.04)$ & $0.20(0.02)$ & $0.44(0.05)$ \\
Lagoon well & MW 3 & NC & $0.39(0.02)$ & $0.45(0.01)$ & $0.32(0.02)$ \\
Field well & MW 7 & BD & BD & BD & $0.02(0.004)$ \\
Dairy II & & & & & \\
Lagoon & & 3.91(0.05) & $6.34(0.17)$ & $1.08(0.04)$ & $5.13(0.55)$ \\
Flush lane & & $7.14(0.51)$ & $3.37(0.19)$ & $1.17(0.08)$ & NC \\
Freestall well 1 & MW 1 & BD & BD & BD & $0.08(0.01)$ \\
Freestall well 2 & MW 2 & BD & $0.04(0.001)$ & $0.25(0.01)$ & NC \\
Lagoon well 1 & MW 3 & $0.36(0.06)$ & $0.30(0.02)$ & $0.07(0.006)$ & NC \\
Lagoon well 2 & MW 10 & NC & $0.07(0.002)$ & $0.13(0.01)$ & NC \\
\hline
\end{tabular}

${ }^{\dagger}$ Watanabe et al., 2008 


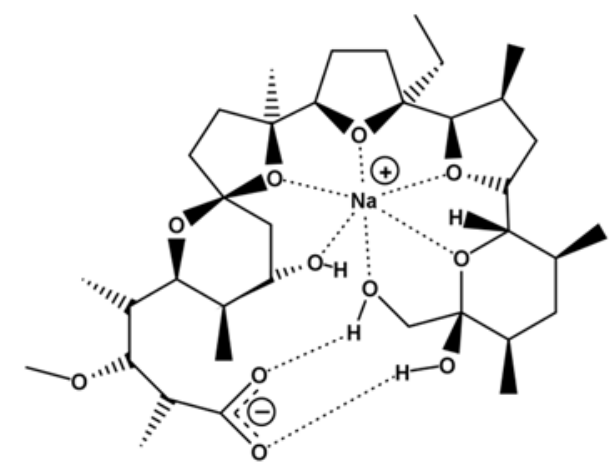

Figure 1. Structure of monensin, an ionophore antibiotic administered to dairy cattle as a feed additive. Structure created with MarvinSketch, Marvin 15.4.20.0, 2015, ChemAxon (http:/www.chemaxon.com)

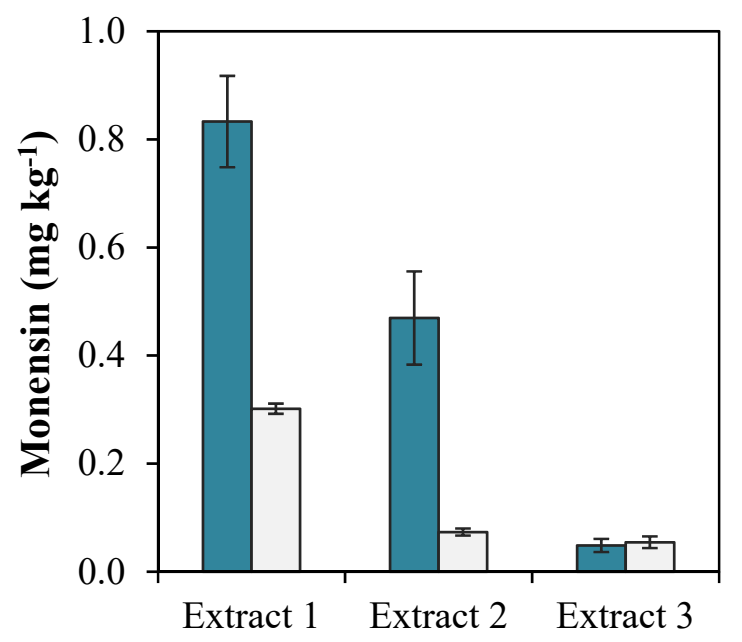

$\square$ Methanol Extractable $\square$ Water Extractable

Figure 2. Methanol- and water-extractable monensin from wet manure following three extractions. Monensin concentration from each manure extract is presented on a dry weight basis. Error bars represent the standard error of quadruplicate samples. 


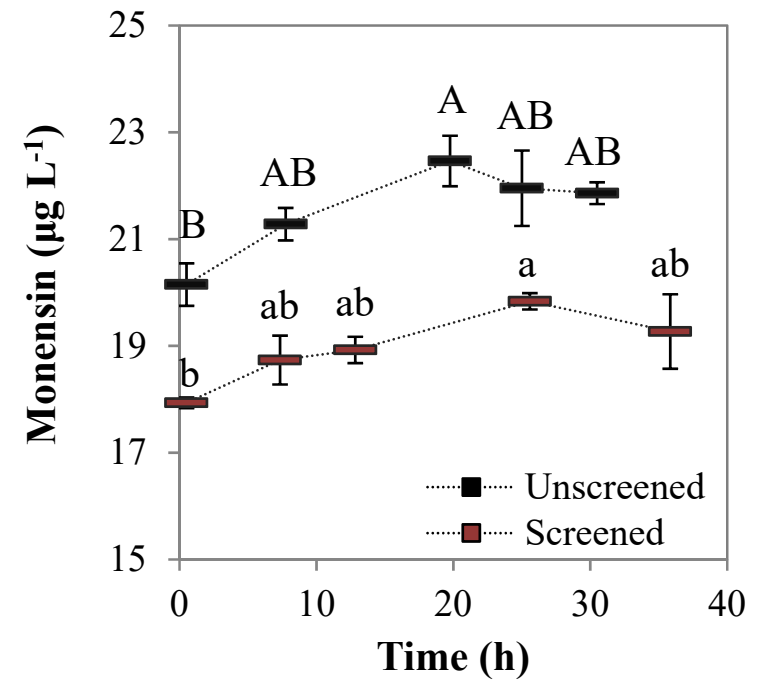

Figure 3. Monensin concentration in screened and unscreened manure in short-term microcosms. Error bars represent the standard error of triplicate samples. Time points that share letters are not significantly different $(\alpha=0.05)$. Statistical comparisons are made within treatment, such that uppercase and lowercase letters cannot be compared.
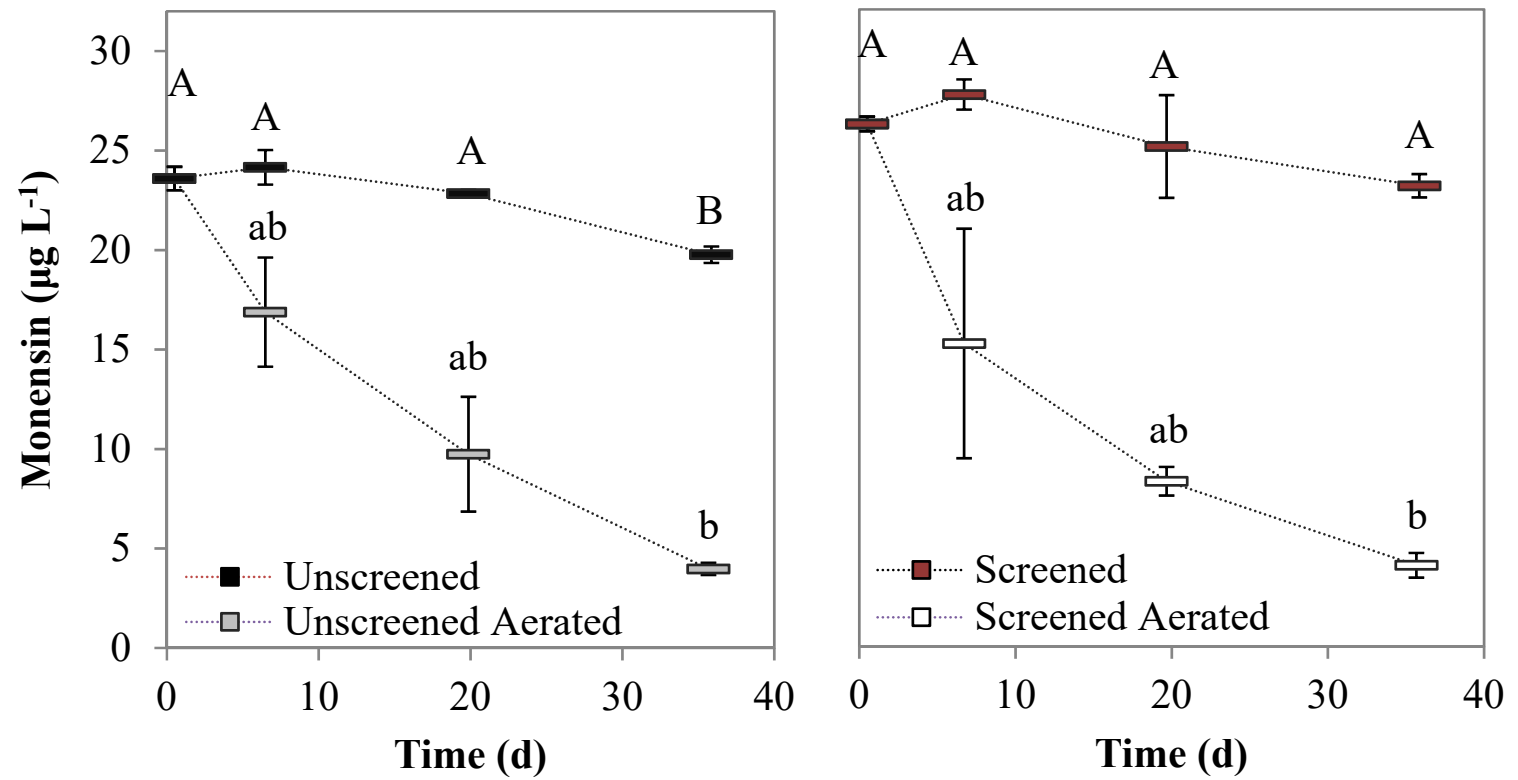

Figure 4. Monensin concentration in screened and unscreened manure in long-term microcosms. Aerated samples are corrected for evaporative loss. Error bars represent the standard error of triplicate samples. Time points that share letters are not significantly different $(\alpha=0.05)$. Statistical comparisons are made within treatment, such that uppercase and lowercase letters cannot be compared. 


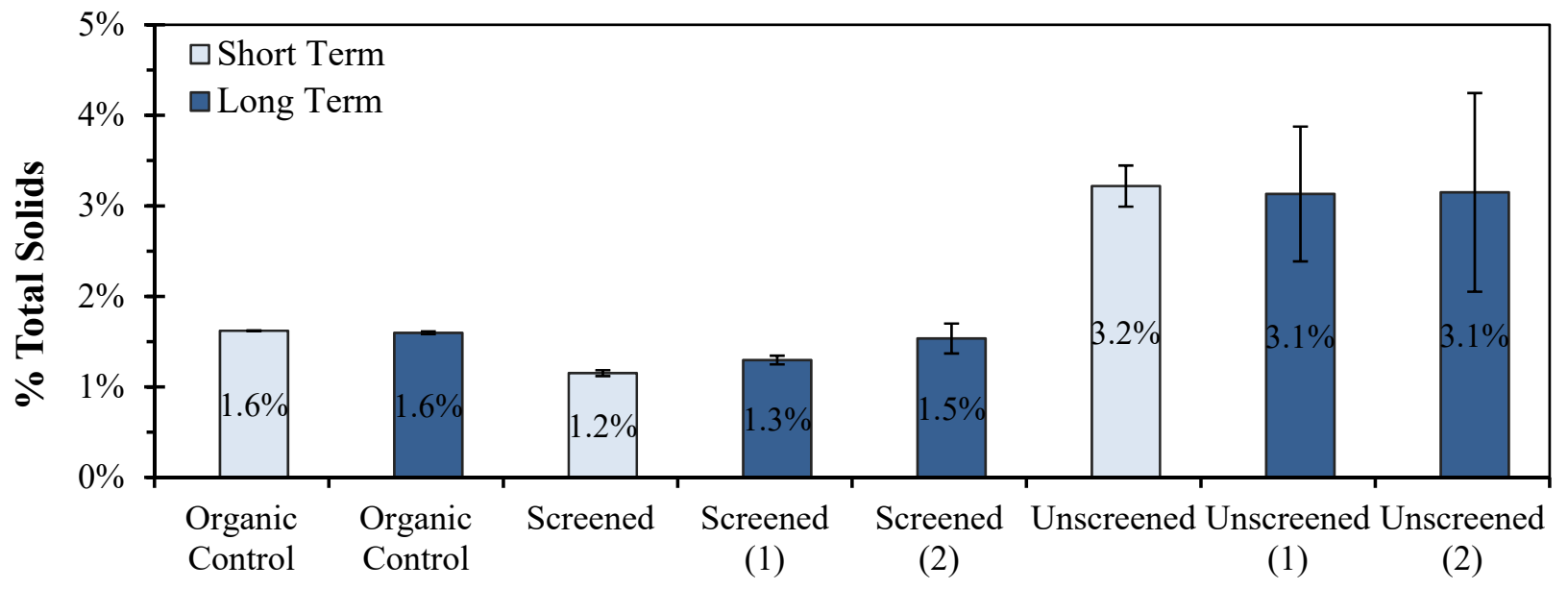

Figure 5. Total solids in organic control, screened, and unscreened manure in short-term and long-term microcosms. Long-term microcosms were constructed from two separate dilutions of manure. Error bars represent the standard error of triplicate measurements.

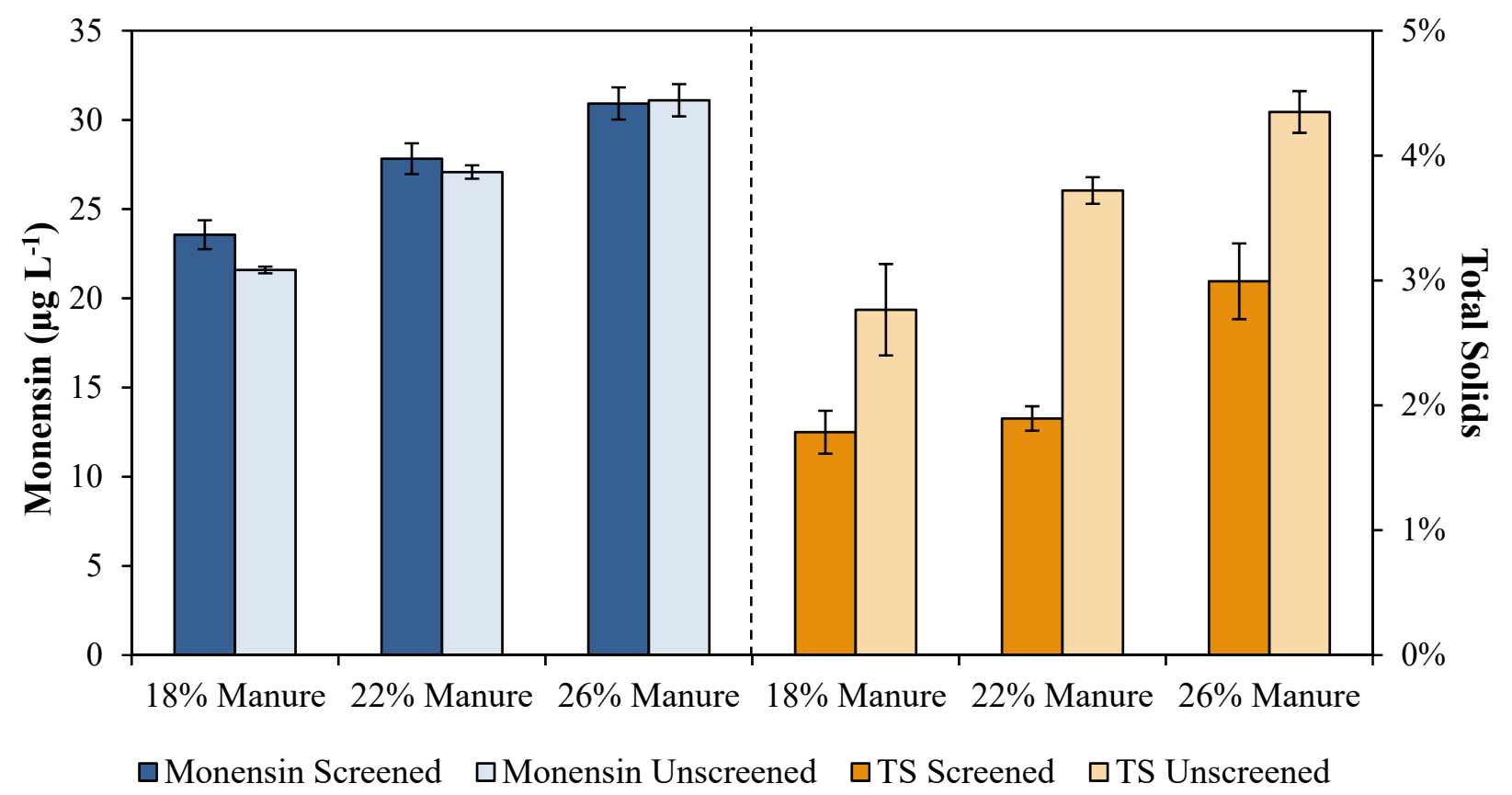

Figure 6. Monensin concentration and total solids in suspensions with 18, 22, and $26 \%$ initial manure (wet weight), with and without screening $(2 \mathrm{~mm})$. Error bars represent the standard error of triplicate samples. 